\title{
Comparison Analysis and Research on the Characteristics of Western Continuing Education and the Influence on the Current Chinese Continuing Education Pattern: A Technique Review
}

\author{
Kewen $\mathrm{HAN}^{1}$ \\ ${ }^{1}$ Jilin Business and Technology College, Jilin Changchun, China,130507
}

\begin{abstract}
In this paper, we conduct research on the characteristics of western continuing education and the influence on the current Chinese continuing education pattern. Continuing education is to leave all the social members after regular school education and mainly for adults education and training activities, people are continuously updated knowledge, develop skills and improve the quality and the quality of life important way. This research compares the differences of the education pattern of the Chinese and the western countries. In the future, we plan to conduct more related literature review work to polis and introduce more in-depth research.
\end{abstract}

Keywords: Continuing Education; Comparison; Education Pattern; Technique Review.

\section{Introduction}

In ordinary colleges and universities in our country mostly in ordinary education and continuing education are on two legs. As two important part of lifelong education system, they are for building learning society well has an important role, it is side key differs somewhat. Normal education mainly through common the university entrance exam by the state administrative department of education approved or registered for full-time higher education record of formal schooling education is given priority to, continue to education is mainly faces the society employed adults outside general education, adult the university entrance exam, higher education self-study exam, lighting and other academic education and non-academic training as the main form of adult education. Organic combination of the two, mutual penetration and mutual complement and mutual promoting, can realize in the true sense of the construction of learning society and lifelong education system and development. Continuing education is to leave all the social members after regular school education, mainly for adults education and training activities, people are continuously updated knowledge, develop skills, improve the quality and the quality of life important way, is an important part of lifelong learning system. In developed countries and continue to education is the same as the normal school education and higher strategic position, at the same time, in the national education and social development plays a very important role [1-3].

Continuing education has made considerable development in our country and has made brilliant achievements in all aspects of the national economic and social development has played a huge role in promoting. However, compared with the continue education developed countries and their advanced experience abroad, the continuing education of our country is still at the primary level of development, the development of our continuing education idea and the management level, mode of running a school and education content, teaching form and so on many aspects, also need to seriously study and draw lessons from international advanced ideas and development of continuing education experience. At present, China's ongoing construction of a harmonious society and new rural construction and urbanization, the urgent need to improve the cultural quality of all the 
social members and working skills, this is just rely on formal school education cannot meet and fully completed, and must be fully rely on and develop the continue education. Therefore, summary and comb the development history of developed countries continue to education and law, explore the experience and enlightenment, which can provide some useful reference to continue the good development of education in our country and the reference, to promote the development of high level of continuing education in our country has the positive significance.

As the solution to the mentioned issues, we conduct research on the characteristics of western continuing education and the influence on the current Chinese continuing education pattern in this paper. Private participation in professional continuing education policy, not only can make policy transparency, and can accelerate the adult self-learning rights consciousness awakening. In today's era of diversification, the interests groups, through its members, financial resources, mobilization ability and the influence factors such as the feeling and decision-making units, and to group decision making model has consultation and other diversified direction. Workplace learning and training, because of its become to improve the quality of life for adults to provide the ability to work with the support of adult basic tools. Under the background of the rapid development of information and communication technology, professional continuing education has been defined as the extension of formal education and has its reality. For that matter, professional continuing education and lifelong learning concept, has become the urgent needs of the adult career development. In expert system for international orientation, market orientation, orientation, orientation and personal orientation, risk management, under the influence of flowing orientation, professional continuing education except as adults own important course of lifelong learning and also existence value of the realization of dynamic demands. The detailed issues will be discussed later.

\section{The Proposed Methodology}

The Characteristics of Western Continuing Education. Education legislation is the basic premise and basis for the development of education undertakings. Law of compulsory education powerful support and impetus and has been subjected to more and more attention in many countries. Developed countries to better promote and manage to continue education, not only with the aid of fiscal policy to give financial support which is using legislative means to ensure. Accordingly with legalization is to continue to the legalization of education management, marks the continuing education has been developed from the initial stage of spontaneous state to rises to the height of the legal system management by the state. Many countries or regions use legal regulation with the professional and technical personnel of enterprises and institutions, the country with the relation between the enterprises and institutions. Its main contents include continuing education goal and the content, enterprise and employee rights and obligations in continuing education, continuing education management system and institutions, continuing education management way and the method, the continuing education mode of investment and funds management, etc. The future with the large-scale development of continuing education, legalized management inevitably more and more urgent, will further improve and perfect. Under globalization, education as a kind of industry of international market prospect broad gradually and the level of competition is increasingly fierce. With the advantages of education resources in developed countries and flexible mechanism, the various training to expand overseas and tentacles extend to all corners of the world.

The concept of life-long education as the leading thought of the continuing education development. Continuing education has broken 
the education closed mode, updated once the traditional concept of education on life and that learning will not end with the end of the school education and promoting the active learning, continue to learn. This has become a developed country guidelines for the development of continuing education system. As an important component of the lifelong education system to education is the concept of lifelong education as the leading thought of the development. Close contact and timely reflect the social economy and the needs of the development of science and technology. From the power of the personnel training specification to develop level, no matter from the professional and curriculum setting of open or from education content choice and updates, or from the planning and development strategy of continuing education or from the perspective of the concrete implementation of continuing education, the continuing education of developed countries under the background of the tightly close to the general practice of economic development and scientific and technological innovation and according to its development and needs to carry out the education training work. In this background, the continuing education is no longer the education institutions and education providers in the market but to entrust unit and education needs of the market. In the following figure one, we use the SWOT analysis methodology method to ensure and analyze the features.

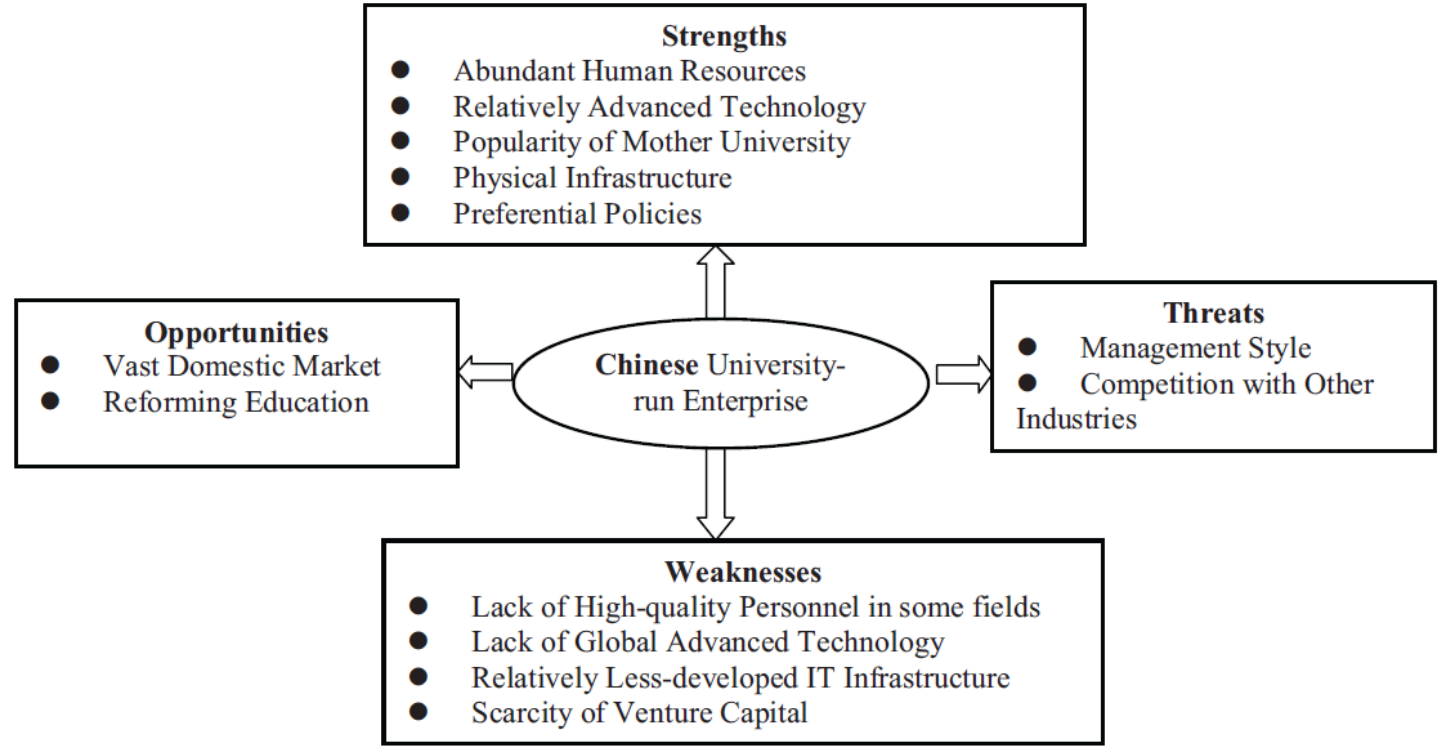

Fig. 1The SWOT Analysis for the Proposed Comparison Research

The SWOT analysis could be de-composited into the following sub-sections. (1) Strengths. To carry out the foundation is better. At present our country most of the colleges and universities have further education institutions and with the corresponding management personnel to carry on the standardized management, and make full use of abundant teaching resources and advantages for teaching and scientific research, the teaching quality guaranteed, under the premise of knowledge broad, a sufficient amount of information, carry out various types and levels of continuing education, actively through extensive international exchanges and cooperation with the introduction of advanced educational ideas and technology. This way of education, the learning time and place are very flexible and can be free to choose courses, freedom to learn at their own pace, and to get tailored learning. Knowledge of species diversity, suitable for different industries, different people, can undertake study in the work, do work and study. Judging from the reaction of a large number of students to the university to continue education, continuing education flexibility has already become the most main reason to attract students. (2) Weakness. 
On-the-job personnel to continue education mechanism is not sound. On the one hand, staff education and the personnel policy, salary and position of employment effectively, let the participants feel the importance and necessity of making a lot of continuing education and training programs fell less than reality. In recent ten years, continuous enrollment expansion of colleges and universities in our country, the number of undergraduate, graduate school increased, and the school of software and hardware facilities equipped with far couldn't keep up with the growth of the number of students, limited teaching resources must be priority assigned to full-time students, the continuing education of always could not get enough attention, the teaching facilities, teacher is restricted, it is restricting the development of the university to continue education. (3) Opportunities. At the present time, escalating the situation of economic globalization, the worker quality requirement enhances unceasingly. Setup of continuing education, the scale of higher education in our country, are based on the demand of the market forecast for the premise, according to the development of the human resources market and the trend of structural change and flexible to develop, so as to ensure social and individual demand for higher education, also meet the needs of social and economic development of applied talents. (4) Threats. The impact of the ordinary university recruitment of students scale expanded year by year. With the advancement of process of popularization of higher education in our country, for ten consecutive years of enrollment expansion to the enrollment of continuing education in our country and development brings the huge impact, continuing education students received a serious threat. Lack of corresponding laws and regulations constraint, entrance threshold is low, quality is low. Currently, some of the colleges of further education institutions for the pursuit of economic benefits, deliberately lower the difficulty of students admission, graduation, management is not standard, certificate of spam. Continue education investment shortage, blindly for enrolment and completely ignore such problems as teaching management and teaching quality, the continuing education of poor students by education conditions. Therefore, adding the features into the Chinese continuing education is urgent and necessary.

The Current Chinese Continuing Education with Modification. The advent of the era of knowledge economy and the establishment of a learning society, improve the status and importance of continuing education. World science and technology revolution and training education revolution is the continued global education rapid development in the innovation and reform and play an enormous social and economic benefits role. As the growth of the various personnel learning needs and the increasingly rich, more and more attention is paid to the development of non-academic education colleges and universities. Non-academic education of institutions of higher learning includes all kinds of education, training and graduate student classes. General prep, ministry assistance, such as type, content involves all kinds of subject education and post certificate, certificate of quality and ability training, and improves the other training. A learning society with the concept of government in the import and development of the world, life-long education thought strongly impact the stage of education and the education of person of outstanding ability, has greatly promoted the development of continuing education, continuing education become the main way to construct lifelong learning system, by many experts call it "career education". Because of this, a concept of life-long education in many countries continue to be the basic ideas of education reform and development, become the guiding principle for the continuing education legislation of various countries, and thus affects the continue education idea and mode of development. Specialization is characteristic of developed countries continue to 
education. For example, the engineering and technical personnel to continue education emphasizes on content closely combining with the new trends, new trend of science and technology and research and development and application of the new requirements. Such as one in the field of technology to get fast development and may be widely used in other departments and then may lack this aspect of the engineering and technical personnel. To combine the advancement of the foreign experience with the Chinese situation, we should conduct more related literature review.

\section{Conclusion}

This paper conducts survey and research on the characteristics of western continuing education and the influence on the current Chinese continuing education pattern. The concept of life-long education as the leading thought of the continuing education development. Continuing education has broken the education closed mode, updated once the traditional concept of education on life and that learning will not end with the end of the school education and promoting the active learning. The combination of western countries' experience is extremely precious for us, in the future, we will introduce more related survey and review on this topic.

\section{References}

[1] Shan, L., Ping, H., School, C. E., \& University, B. S. (2014). Development research on professional competence of physical education teacher in school. China School Physical Education.

[2] Ming-yue, X., Tao, W., Qin, H., Li, Z., Yue-xin, H., \& Lin, L., et al. (2014). The investigation and analysis of the status and influencing factors of the continuing medical education in yunnan province. Journal of Kunming Medical University.

[3] Education J O A A C, Spr V N P. Research Areas in Adult and Continuing Education[J]. Journal of Adult \& Continuing Education, 2014 , 1989(44):47-54. 